\title{
A INCLUSÃO DE DOIS DEFICIENTES VISUAIS NA ESCOLA: SUAS PERSPECTIVAS NA REDE PÚBLICA E PRIVADA
}

\author{
Paula Jucá de Sousa'; Fernando Morais Rodrigues ${ }^{2}$ \\ ${ }^{1}$ Professora Mestre em Novas Tecnologias Digitais do Instituto Federal de Educação, \\ Ciência e Tecnologia do Tocantins, Paraíso do Tocantins-TO, Brasil. \\ E-mail: paulajuca@ifto.edu.br \\ ${ }^{2}$ Professor Doutor do Instituto Federal de Educação, Ciência e Tecnologia do \\ Tocantins, Paraíso do Tocantins-TO, Brasil.
}

Recebido em: 15/02/2020 - Aprovado em: 15/03/2020 - Publicado em: 30/03/2020 DOI: 10.18677/EnciBio_2020A1

\begin{abstract}
RESUMO
A inclusão escolar se constitui como uma desconstrução de preconceitos e a garantia de direitos essenciais para a manutenção de uma vivência mais íntegra, segura e também a visibilidade social do sujeito. Esta visibilidade não subentende apenas no sentido de colocar as pessoas com deficiências na escola, mas também de fazer com que este se sinta integrado ao ambiente. Levando em consideração este contexto, o presente artigo abordará a inclusão na perspectiva de dois estudantes com deficiência visual, sendo um da escola pública e outro de uma escola privada. Sendo assim averigou-se se as propostas de inclusão ofertadas pelas instituições têm sido satisfatórias para os sujeitos tendo em vista sua adequação e suas mais diversas relações sociais. Desta forma, apresentou-se a questão da neuroplasticidade em relação ao cego no ambiente escolar sob o ponto de vista da interatividade e suas relações com o meio. Para a obtenção de dados realizou-se pesquisa qualitativa por meio de estudo de caso, com base na técnica descritiva e aportou-se às teorias sociointeracionistas.
\end{abstract}

PALAVRAS-CHAVE: deficiência visual, inclusão, interação

\section{THE INCLUSION OF THE VISUALLY DISABLED IN SCHOOL: YOUR PERSPECTIVE}

\begin{abstract}
School inclusion constitutes a deconstruction of prejudices and the guarantee of essential rights for the maintenance of a more complete, safe experience and also the subject's social visibility. This visibility does not imply only in terms of putting people with disabilities in school, but also making them feel integrated into the environment. Taking this context into account, this article addresses inclusion from the perspective of the visually impaired student in public schools. Thus, it was investigated whether the inclusion proposals offered by the institutions have been satisfactory for the subjects, considering their adequacy and their most diverse social relations. Thus, the question of neuroplasticity in relation to the blind in the school environment was presented from the point of view of interactivity and its relations with the environment. In order to obtain data, qualitative research was carried out
\end{abstract}


through a case study, based on the descriptive technique and applied to sociointeractionist theories.

KEYWORDS: visual impairment, inclusion, interaction

\section{INTRODUÇÃO}

A partir da Lei de Diretrizes e Bases (LDB n 9394/96) as práticas de inclusão no Brasil com vistas ao acolhimento da diversidade tornou-se mais intensiva, principalmente nas instituições escolares. É notória as políticas públicas implantadas com o intuito de formar gestores e educadores inclusivos; todavia o que se observa na prática é que a escola ainda permanece demonstrando estar impossibilitada em atender as demandas necessárias para a formação integral do estudante com deficiência (BRASIL, 1996).

Atribui-se à escola a responsabilidade de deixar de excluir para incluir e educar a diversidade dos seus públicos, numa perspectiva de sucesso de todos e de cada um, independentemente de cor, raça, cultura, religião, deficiência intelectual, psicológica ou física (SANTOS, 2018). Desta forma, as reformas educacionais e questionamentos sobre o papel da escola exigem que se repense a prática pedagógica tendo a ética, a justiça e os direitos humanos como parâmetro de ação educativa para ensinar a todos os alunos, sem discriminação e com métodos e práticas de ensino especializado (LIMA, 2018) que devem adequar à nova realidade educacional através da construção de políticas e práticas institucionais e pedagógicas que garantam o incentivo da qualidade de ensino a todos (BRASIL, 2001b).

Neste contexto, a discussão está centrada na inclusão do estudante como um todo, ou seja, não só o acesso aos conhecimentos curriculares, mas a garantia de que este se sinta pertencente ao meio que está inserido. À vista disso, as Orientações Curriculares Nacionais para o Ensino Médio (OCNEM) trazem uma seção intitulada Inclusão/Exclusão, na qual ressaltam que:

\footnotetext{
"não basta expor os alunos às propostas educativas sociais, isto resultaria em inserir (colocar, introduzir, aderir) os excluídos, mas não em incluí-los (fazer parte, figurar entre outros, pertencer, envolver) socialmente" (BRASIL , 2006, p. 96).
}

Em 1990, delegados de 155 países e representantes de 150 organizações governamentais e não governamentais participantes da Conferência sobre a Educação para Todos, reunidos em Jomtien, na Tailândia, aprovaram a Declaração Mundial sobre a Educação para Todos, que reafirma o direito à educação como direito humano fundamental e aponta a necessidade de maiores esforços para atender aqueles que têm necessidades especiais. Assim, a inclusão de pessoas com deficiência e alunos sem deficiência surge legalmente no Brasil em 1996 através da LDB 9394/96, tendo início por meio do movimento Educação para Todos (BRASIL, 1996).

No âmbito da legislação brasileira é percebido o não cumprimento do que de fato é estabelecido como direito aos deficientes (DUTRA, 2017). Segundo Vygotsky (1997), é importante observar e compreender como o estudante com deficiência visual está inserido no contexto educativo, e apesar das dificuldades encontradas em seu convívio escolar como ele consegue obter aprendizagens significativas. Vale ressaltar a interação com o meio e entre seus pares, onde o mesmo terá a 
possibilidade de trocas e de articular o conhecimento. Tal realidade está de acordo com os pressupostos de Vygotsky (1997) para quem a deficiência é muito mais social que biológica, sendo as limitações e fragilidades impressas pelo contexto social, contexto este que provoca e estimula conseguindo naturalizar e desenvolver aprendizagens que rompem com a ideia de deficiência.

A aprendizagem é o processo no qual o indivíduo apropria-se ativamente daquilo que seu grupo social conhece e fornece. $O$ desenvolvimento dessa mesma aprendizagem é processado por meio da construção ativa da criança durante a relação que estabelece com o físico e social (VYGOTSKY, 1998).

Contudo, é percebido que o sujeito muitas vezes, torna-se refém de uma educação inclusiva defasada por não serem difundidas metodologias que permeiam as realidades do educando. Nesse sentido, se faz necessário a ambientação de todos envolvidos na comunidade escolar, na qual os sujeitos possam a praticar relações de afetividade, trocas, como fator preponderante à inter-relação social/educacional.

Ressalta-se que cada indivíduo possui maneiras particulares de aprender e de apreender o mundo externo; assim, a proposta de investigar estratégias e estilos de aprendizagem estão relacionadas à influência desses na vida do estudante (WALTER et al., 2017). Paiva (2019), define os estilos de aprendizagem como "abordagens gerais" que envolvem aspectos cognitivos, afetivos (emocional e atitudinal) e sociais.

Levando em consideração este contexto, o presente artigo visa abordar a inclusão na perspectiva do estudante com deficiência visual tanto da escola pública quanto na escola privada. Neste sentido, objetivou-se averiguar se as propostas de inclusão ofertadas pelas instituições têm sido satisfatórias para os sujeitos, tendo em vista sua adequação e relação social dentro do ambiente escolar.

\section{MATERIAL E MÉTODOS}

Para identificar de que forma o deficiente visual se sente no ambiente escolar, foi realizada uma entrevista com dois estudantes de curso Superior da cidade do Rio de Janeiro no mês de agosto do ano de 2019. A mesma foi realizada através do uso do wattsapp. Os participantes da pesquisa eram um de instituição pública e outro recentemente formado em uma instituição privada. Concordando em participar, os estudantes foram convidados a assinar o Termo de Consentimento Livre e Esclarecido.

Assim, levou-se em consideração a neuroplasticidade em relação ao ambiente escolar, tendo em vista a interatividade e suas relações com o meio. Para a análise dos dados comparou-se a realidade de cada um em relação a sua vivência escolar no que tange suas expectativas, relações pessoais e sua formação tanto educacional quanto pessoal, caracterizando a inclusão dos estudantes evidenciadas através das teorias sociointeracionistas.

A partir de uma metodologia qualitativa que propõe, sobretudo, sobre a interpretação dos dados, levando em cosideração a sensibilidade, a pesquisa limitou-se em descrever as falas dos entrevistados de forma íntegra. Neste sentido, procurou-se de maneira sistemática interpretar o corpus adotando os seguintes procedimentos:

- elaboração de um roteiro de entrevista;

- realização das entrevistas, que foram realizadas utilizando o recurso tecnológico whatsapp; 
- escuta, transcrição e anotação das impressões;

- análise das entrevistas.

Tendo em vista identificar de que forma o deficiente visual se sente no ambiente escolar, o questionário versou sobre 10 indagações relacionadas tanto à relação que este teve não só com os professores e colegas de sala, mas com o ambiente escolar como um todo. Para fins de identificação, o Aluno W corresponde ao estudante da instituição Pública e o Aluno Z o estudante da instituição privada.

\section{RESULTADOS E DISCUSSÃO}

Inicialmente, para que se tivesse uma visão ampla, mencionou-se o relacionamento que estes dois alunos possuem com a comunidade escolar como um todo.

QUADRO 1: Interação dos alunos com necessidade específica visual com a comunidade escolar

\section{Aluno W}

"Eu não conheço muita gente que trabalha lá. Então, só os professores e algumas pessoas. A relação é boa porém são poucas que eu conheço. Não tenho relacionamento e não converso com pessoas de outros departamentos. Fora os professores a única pessoa que eu converso é o psicólogo, tanto pelo wattsapp quanto pessoalmente".

\section{Aluno Z}

"Nas duas instituições, meu relacionamento com os alunos são bons, na maioria das vezes eles me ajudam. A minha relação com os professores, apesar deles não terem preparo de lidar com a minha deficiência, também é bom e com os demais da instituição não tenho relacionamento".

Por meio do discurso dos estudantes, constatou-se que o relacionamento destes está restrito aos colegas de sala e ao professor, não havendo interação entre os sujeitos que constituem a comunidade escolar. Segundo Vygotsky (2003) o desenvolvimento do indivíduo é resultado do processo sócio-histórico, isto é, o sujeito adquire conhecimento por meio da interação com o ambiente social e entre os pares no qual está inserido.

Levando em consideração que o ensino em sala de aula associa-se diretamente à figura do professor, questionou-se aos entrevistados se eles consideravam que os professores da instituição estão preparados para atendê-los.

QUADRO 2: Percepção dos alunos com necessidade especifica visual em relação aos professores

\section{Aluno $\mathbf{W}$}

"Não, eu acho que não, não estão preparados não só para mim como pra nenhum outro deficiente visual. E se dão suporte, alguns sim, outros não".

\section{Aluno Z}

"Os professores não têm o conhecimento de como lidar com o aluno que tem deficiência visual. Apesar deles não terem preparo de tarem lidando com a minha deficiência na maioria das vezes eles tentam me ajudar, apesar de muitas das vezes não conseguirem, eles trabalham muito com questões de imagens, xerox e isso me atrapalha bastante". 
Com efeito, constatou-se na fala dos dois estudantes que é perceptível a dificuldade que os educadores enfrentam ao lidar com o aluno com necessidades especificas visuais em sala. Isso se confirma quando o Aluno $Z$ descreve as formas de aplicação das atividades. Entretanto, estes reconhecem o esforço de alguns profissionais docentes ao tentar dar suporte na execução das tarefas. Desta forma, a Proposta de Diretrizes para a Formação de Professores da Educação Básica delineia alguns aspectos para a garantia da inclusão quanto ao papel do professor destacando prioritariamente:

\begin{abstract}
"Orientar e mediar o ensino para a aprendizagem dos alunos; responsabilizar-se pelo sucesso da aprendizagem dos alunos; assumir e saber lidar com a diversidade existente entre os alunos; incentivar atividades de enriquecimento curricular; elaborar e executar projetos para desenvolver conteúdos curriculares; utilizar novas metodologias, estratégias e material de apoio; desenvolver hábitos de colaboração e trabalho em equipe" (BRASIL, 2001a).
\end{abstract}

Não obstante, o espaço físico também é um fator que contribui para que os estudantes se sintam seguros e inseridos no ambiente escolar. Nesta perspectiva, a questão seguinte indagou se o espaço físico contribuia para a independência e interação deles com o meio.

QUADRO 3: Percepção dos alunos com necessidade especifica visual em relação aos ambiente escolar

\begin{tabular}{l} 
Aluno W \\
"Aquelas rampas contribui sim para a gente que tem deficiência visual, corrimão também, evita da \\
gente cair de um lugar alto, mas me locomovo através da ajuda das pessoas, mesmo com a \\
bengala eu preciso da ajuda das pessoas" \\
\hline Aluno Z \\
"A estrutura em si da universidade por ser um prédio antigo não é acessível não só pra mim que \\
sou deficiente visual mas pros outros alunos também que tem dificuldade em uma locomoção. Na \\
privada o prédio é mais novo tem elevador, corrimão, piso guia e é mais fácil para me locomover. \\
Tem uma sala de recursos com aplicativos o Dosvox, que me auxiliam melhor."
\end{tabular}

Verificou-se que no discurso do Aluno W, da escola pública, que a instituição possuia os recursos necessários para a locomoção, no entanto este dependia do auxílio de outras pessoas. Já segundo o Aluno $Z$ na instituição pública não se segue os padrões necessários para que haja maior interação entre ele e o meio, além de não possuir recursos para um melhor desempenho. Em contrapartida, na instituição privada o espaço possui maior acessibilidade e recursos para melhor atendê-lo. Conforme Xavier (2016), a Diretriz Operacional da Educação Especial:

\footnotetext{
"os sistemas de ensino devem disponibilizar os recursos da educação especial para que os alunos tenham os recursos e as condições de acesso ao currículo, promovendo os materiais didáticos, aos espaços e equipamentos, aos sistemas de comunicação e informação e ao conjunto das atividades escolares. Sala de recursos multifuncional: espaço físico, mobiliários, materiais didáticos, recursos pedagógicos e de acessibilidade e equipamentos específicos".
} 
Sequencialmente foi perguntado aos estudantes se eles consideravam que a instituição em que estavam inseridos estava preparada para atendê-los.

QUADRO 4: Percepção dos dois alunos com necessidade especifica visual em relação às instutições

\title{
Aluno W
}

"Eu acho que algumas coisas sim e outras não, por exemplo as questões de rampas, corrimão aqueles piso guia ajuda muito, nesse caso aí facilita muito, facilita sim, mas para atender em outras coisas não.

\section{Aluno Z}

"A universidade não está preparada e não corresponde a minha expectativa pois o espaço físico não tem acessibilidade e não só o espaço físico os professores não têm o conhecimento de como lidar com um aluno que tem uma deficiência visual."

Apesar de abordar que os recursos físicos adaptados contribuem para a inclusão, o Aluno $W$ ressaltou que a instituição não encontra-se totalmente adequada. Em contrapartida, o Aluno $Z$ enfatizou que as duas instituições não estão preparadas, e isto não está relacionado somente ao espaço físico, mas na capacitação dos professores para lidar com os alunos com necessidades especificas visuais. A UNESCO ressalta que:

\begin{abstract}
"As escolas inclusivas devem reconhecer e responder às diversas necessidades de seus alunos, acomodando tanto estilos como ritmos diferentes de aprendizagem e assegurando uma educação de qualidade a todos através de currículo apropriado, modificações organizacionais, estratégias de ensino, uso de recursos e parceiras com a comunidade (...) Dentro das escolas inclusivas, as crianças com necessidades educacionais especiais deveriam receber qualquer apoio extra que possam precisar, para que se lhes assegure uma educação efetiva “(...) (UNESCO, 1994).
\end{abstract}

Tendo em vista a importância do relacionamento do sujeito com o meio em que está inserido, indagou-se aos participantes acerca do relacionamento que estes possuiam com os colegas de sala.

QUADRO 5: Percepção dos dois alunos com necessidade especifica visual em relação à interação com os demais colegas de sala

\footnotetext{
Aluno W

"bom a relação com os colegas de sala é boa demais, eu graças a Deus fiz muitas amizades la, tem algumas pessoas que agente não se fala mas eu não sei porque, eu não sei mas sou tranquilo se falarem comigo eu falo normal, mas tipo assim não fico chateado não com as pessoas que não falam comigo."
}

\section{Aluno Z}

"relacionamento com os alunos são bons graças a Deus na maioria das vezes me ajudam."

A priori os dois estudantes relataram que têm um bom relacionamento, porém o aluno $\mathrm{W}$ deixou subentendido que existe um certo distanciamento de alguns 
colegas. Corroborando com Lauriti e Molinari (2015), na interação afetiva com outro sujeito, cada sujeito intensifica sua relação consigo mesmo, observa seus limites e, ao mesmo tempo, aprende a respeitar os limites do outro. A afetividade é necessária na formação de pessoas felizes, éticas, seguras e capazes de conviver com o mundo que a cerca. As autoras ressaltam ainda que:

\begin{abstract}
Afeto e cognição constituem aspectos inseparáveis, presentes em qualquer atividade. A afetividade se estrutura nas ações dos indivíduos. $O$ afeto pode, assim, ser entendido como energia necessária para que a estrutura cognitiva possa operar. Ele influencia a velocidade com que se constrói o conhecimento, pois, quando as pessoas se sentem seguras, aprendem com mais facilidade (LAURITI; MOLINARI, 2015).
\end{abstract}

Com o propósito de identificar as expectativas dos estudantes ao ingressarem na instituição e a visão destes após a convivência no ambiente, as questões seis e sete versaram sobre este aspecto.

QUADRO 6: Perpescitvas dos dois alunos com necessidade especifica visual ao ingressarem e após o ingresso na instituição de ensino.

\title{
Aluno $\mathbf{W}$
}

"Minhas expectativas ao ingressar na instituição era aprender coisas novas a cada dia e aprender tipo coisas que eu tenho dificuldades. A expectativa que eu tinha em tirar minhas dúvidas ter um horário de atendimento de o professor me explicar o que não entendi em algumas disciplinas isso não mudou"

\section{Aluno Z}

"Na pública eu tinha uma expectativa maior por ser uma Universidade Federal e alcançar um local mais acessível. Hoje em dia não corresponde mais às minhas expectativas pois lá não tem acessibilidade nenhuma, isso não só o espaço físico mas os professores que também não sabem lidar com alunos com deficiência visual"

O que deveria ser inclusão, acaba a cada dia excluindo e não dando possibilidades aos estudantes de terem uma trajetória para que de fato eles possam vivenciar novas expectativas com o mundo ao seu redor. A fim de sondar o sentimento de pertencimento ao ambiente escolar, as questões subsequentes abordaram acerca do que mais os incomodam e o que mais os motivam em permanecer no ambiente escolar.

QUADRO 7: Percepção dos dois alunos com necessidade especifica visual sobre a motivação em permanecer no ambiente escolar

\footnotetext{
Aluno W

"Me sinto bem por encontrar as pessoas que eu converso com meus amigos que estudam comigo e outras que não estudam umas três pessoas que eu converso sinto bem porque encontro com eles meus amigos que estudam lá.

Aluno Z

"Me sinto bem, apesar de que sinto dificuldades em ter acesso a alguns ambiente mas de modo geral acho bom estar na universidade"
}

Corroborando com Paiva (2019), o modo de como o ser humano reagirá a determinadas situações de afeto ou quaisquer que sejam as situações pelas quais passar, dependerá muito do meio. Uma vez que o meio molda a personalidade 
humana. Neste sentido, observou-se na fala do estudante W que este se sente bem ao se relacionar com os colegas de sala, apesar de ressaltar que não contém contato com os demais sujeitos da comunidade escolar. De acordo com Monteiro e Gaspar (2016), a escola, um dos meios de influência externa, é um espaço legítimo para a construção da afetividade, uma vez que está centrada na intervenção sobre a inteligência, de cuja evolução depende a evolução da afetividade.

Em relação ao sentimento de incômodo dentro do ambiente escolar e a motivação de permanência dos dois estudantes foram observados aspectos relevantes, principalmente no que tange à afetividade e a interação deles com o meio.

QUADRO 8: Percepção dos dois alunos com necessidade especifica visual sobre os as dificuldades encontradas no ambiente escolar

\section{Aluno W}

"O que mais me incomoda é quando querem me tratar diferente. Esse meu olho aqui é só um detalhe esse problema é só um detalhe que quando eu tô junto com essas pessoas aí na escola quando eu tô aí sorrindo eu tô brincando às vezes até falando alguma besteira é um momento que eu esqueço desse problema das vista. Parece que eu aqui tô normal parece que eu tô igual a todo mundo aqui. Só quando eu saio pra fora que a gente lembra do problema mas quando eu to ai mesmo divertindo e rindo com o pessoal eu nem lembro do meu problema. sempre nos meus momentos felizes eu tô feliz eu esqueço do meu problema. Mas é isso me tratar de maneira diferente. O que mais me motiva a permanecer é aprender a ser independente mas eu vou colocar o ser independente aqui em primeiro lugar porque independência é uma coisa que eu quero muito não só aí eu quero conquistar a independência aqui fora também porque eu não vou viver aí dentro pra sempre então eu quero conquistar a minha independência aqui fora eu quero aprender a fazer igual aos cegos que eu vejo passando em reportagens os cegos que andam pra todo lado eu quero sair sozinho coisas assim e aprender aprender muito é isso que me motiva a permanecer".

\section{Aluno Z}

"O que mais me motiva é poder aprender alguma coisa e o que mais me incomoda é não ser atendido com recursos e acessibilidade. Falta de acesso a quase tudo dentro da universidade e ter que depender de outras pessoas".

Vale ressaltar, que o ser humano é passível de construções ao longo de sua vida e se faz necessária as diversas formas de interações. Com isso o cotidiano se faz presente na vida de todos e a construção da personalidade é permeada através dos modelos culturais desenvolvidos nos mais diversificados ambientes transitados ou até mesmo construídos.

Ademais, salienta-se o hibridismo contemporâneo cultural, social e até mesmo na vida escolar/acadêmica, todas essas questões corroboram para um desenvolvimento interacionista dos sujeitos e as mais diversas construções que caracterizarão sua trajetória de vida.
"A perspectiva epistemológica do interacionismo, representada pelo pensamento de Piaget, é uma síntese do empirismo e do racionalismo. O autor põe em xeque as idéias de que o conhecimento nasce com 0 indivíduo ou é dado pelo meio social. Afirma que o sujeito constrói o conhecimento na interação com o meio físico e social, e essa construção vai depender tanto das condições do indivíduo como das condições do meio". (DARSIE, 1999).

Para Vygotsky (1982), todos são diferentes e por essa razão tem-se muito a aprender uns com os outros. As diferenças são o ponto principal que caracteriza que 
ninguém é detentor do saber e sim através das interações com o diferente e entre os pares e meio social/cultural que viabilizará uma transformação no eu de cada indivíduo, possibilitando e aguçando cada vez mais possibilidades e interesse a novas aprendizagens. Vygotsky (1982), afirma que:

\begin{abstract}
"não nega que exista diferença entre os indivíduos, que uns estejam mais predispostos a algumas atividades do que outros, em razão do fator físico ou genético. Contudo, não entende que essa diferença seja determinante para a aprendizagem. Ele rejeita os modelos baseados em pressupostos inatistas que determinam características comportamentais universais do ser humano, como, por exemplo, expressam as definições de comportamento por faixa etária, por entender que o homem é um sujeito datado, atrelado às determinações de sua estrutura biológica e de sua conjuntura histórica".
\end{abstract}

Levando em consideração os aspectos apresentados pelos estudantes, observou-se que as realidades institucionais são muito parecidas. Apesar de uma possuir recursos apropriados para a inclusão do deficiente visual e a outra não, a discussão centra-se muito mais no aspecto sociointeracionista.

É notória as dificuldades enfrentadas pelos dois estudantes na relação com os outros sujeitos da comunidade escolar, o que comprova que a inclusão ainda está restrita à sala de aula. Ademais, sinala-se os obstáculos vividos pelos professores que por vezes não conseguem adequar-se à realidade dos estudantes. Conforme cita Correia e Fernandes (2016):

\begin{abstract}
"O processo de inclusão de alunos com necessidades especiais deve atender a todos, sem distinção, incorporando as diferenças no contexto escolar, o que exige transformação na organização da escola. Essa transformação passa obrigatoriamente por uma política de formação e educação continuada para professores, adaptações do ambiente escolar e novas metodologias que se adequem a necessidade de cada aluno. $\mathrm{Na}$ educação inclusiva o aluno constrói o seu conhecimento de acordo com suas capacidades, expressam suas ideias livremente e participam efetivamente do processo de ensino e aprendizagem "(CORREIA; FERNANDES, 2016).
\end{abstract}

O estudante as vezes sente-se desestimulado por não receber o que imaginou, as fomas de ensino nem sempre são coerentes. Então, é fundamental novos olhares e conhecimentos diferenciados tentando entender esse hibridismo de informações e práticas que o profissional da educação deve ter para com esse sujeito, aprimorando-se sempre com formações continuadas no tocante ao melhor desenvolvimento do estudante.

Tal situação levanta uma diversidade de questionamentos, que de fato impacta direta e indiretamente na vidas desses estudantes que por sua vez estão a beira da exclusão social/escolar. Para tanto se faz necessário cada vez mais investigar, questionar, pesquisando de fato para que se tenham respostas e práticas metodológicas coerentes para todos os envolvidos no ambiente educacional.

\title{
CONCLUSÃO
}

Constatou-se que mesmo as instituições que possuem estrutura física adaptadas e recursos adequados, a inclusão está aquém da estrutura física. Notouse que as instituições escolares devem atentar-se à inclusão não no sentido de inserir mais uma matrícula em um determinado sistema, e sim ter, a real ENCICLOPÉDIA BIOSFERA, Centro Científico Conhecer - Jandaia-GO, v.17 n.31; p. 92020 
responsabilidade em promover uma educação inclusiva atrelada ao ambientalismo, questões sociais, a diversidade das múltiplas formas de aprendizagens conscientizando sempre todos envolvidos no processo educacional e a formação que se faz necessária não somente ao professor, mas sim a todos os que estão envolvidos na instituição escolar.

Para tanto, é importante que o professor tenha um olhar diferenciado para o estudante com necessidade específica visual, possibilitando diferentes formas metodológicas difundindo apropriações na dificuldade do aluno e inserindo cada vez mais o mesmo no ambiente educacional permitindo valorizar suas potencialidades.

Diante do exposto salienta-se, que é de suma importância que a escola tenha um modelo multimodal metodológico, atrelado ao olhar questionador evidenciado quem é esse sujeito e qual a perspectiva deste em relação ao curso escolhido. Desse modo cabe aos profissionais da instituição uma diagnose atrelada ao que se tem como realidade do estudante, para que a partir desse princípio dialogar para que se obtenha sucesso na construção no processo.

Assim, também é interessante ressaltar a pedagogia de projetos e sequências didáticas para melhor apropriação e interação com os sujeitos, uma vez que se faz necessária para um conhecer o outro e mutuamente. Contudo, as formas de trocas caracterizam uma aproximação que relaciona-se a afetividade walloriana indicando fatores relevantes as mais significativas formas de aprendizagens.

Logo, o olhar que deve ter sobre o estudante é que este tenha total participação em todos os ambientes, aprimorando um diálogo contextualizando todas as formas de comunicação e aprendizagens, difundindo cada vez mais o modelo interacionista de Vygostky atrelado não somente na comunicação dos pares/alunos e sim pares/instituição e comunidade escolar. Ou seja, as instituições escolares têm que passar a enxergar o aluno com necessidade específica visual sob o olhar dele, levando em consideração os sentimentos de pertencimento que este possui pelo ambiente. Ainda mais, entender que é a escola que tem que ser incluída e não o estudante.

\section{REFERÊNCIAS}

BRASIL. Secretaria da Educação Básica. Orientações Curriculares para o Ensino Médio. Ciências Humanas e suas Tecnologias. Conhecimentos de Sociologia. p.100-133, 2006.

BRASIL. Ministério da Educação. Secretaria de Educação Especial. Diretrizes Nacionais para a Educação Especial na Educação Básica. Secretaria de Educação Especial - MEC/SEESP, 2001a. Disponível em: < http://portal.mec.gov.br/seesp/arquivos/pdf/diretrizes.pdf>. Acesso em: 01 junho. 2018.

BRASIL. Ministério da Educação. Decreto 3956/01. Brasília, out. 2001b.

BRASIL. Lei de Diretrizes e Bases da Educação Nacional. Lei número 9394, 20 de dezembro de 1996.

CORREIA, A. M.; FERNANDES, P. Educação Especial: limites e potencialidades da educação inclusiva. 2016. ISSN 2525-7668. 
DARSIE, M.M.P.; A reflexão distanciada na construção dos conhecimentos profissionais do professor em curso de formação inicial. TESE (Doutorado) Faculdade de Educação da Universidade de São Paulo: USP, São Paulo 1999.

DUTRA, S. R. A inclusão dos deficientes físicos no mercado de trabalho. Revista Jurídica da Faculdade de Direito de Santa Maria-FADISMA, v. 12, n. 1, 2017. ISSN 1982-5552.

LAURITI, N.C; MOLINARI, S.G. Perspectivas da alfabetização. Paco Editorial. 2015.

LIMA, F. R. D. S. Literatura e prática pedagógica: caminhos para a construção de uma consciência social. 2018.

MONTEIRO, I. C.; GASPAR, A. Um estudo sobre as emoções no contexto das interações sociais em sala de aula. Investigações em Ensino de Ciências, v. 12, n. 1, p. 71-84, 2016. ISSN 1518-8795.

MARTINS, G. P. T. C.; XAVIER, A. P. Imersões Cotidianas na Educação Inclusiva: Múltiplos Olhares, Múltiplos Saberes. Appris Editora e Livraria EireliME, 2017. ISBN 8547307516.

PAIVA, M. M. S. A Afetividade e o Processo Ensino-Aprendizagem. 2019.

SANTOS, M. M. R. D. Educação inclusiva: desafios, possibilidades e enfrentamentos na prática de gestão escolar. 2018.

UNESCO. Diez aspectos de la Educación para Todos. Disponível em http://www.unesco.org/es/ efa/the-efa-movement/10-things-to-know-about-efa/ Acesso em: 25 de maio de 2018.

VYGOTSKY, L. S. A formação social da mente. São Paulo: Martins Fonte, 2003.

VYGOTSKY, L. S. O desenvolvimento psicológico na infância São Paulo: Martins Fontes, 1998.

VYGOTSKI, L. S. Obras Escogidas. V - Fundamentos de defectologia. Tradução Júlio Guillermo. Blank. Madrid: Visor, 1997.

A construção do pensamento e da linguagem. São Paulo: Martins Fontes, 1982.

XAVIER, A. V. O. A Inclusão da Pessoa com Deficiência na Escola Regular. Arcos. 2016. Disponível em: http://www.arcos.org.br/artigos/a-inclusao-da-pessoacom-deficiencia-na-escola-regular/. Acesso em 29 de novembro de 2019.

WALTER, C. E.; FORTES, P.J.; STETTINER, C.F. A influência dos estilos de aprendizagem no desempenho de grupos de trabalho. Revista de Estilos de Aprendizaje. V. 10, n. 20, 2017. ISSN 1988-8996. 